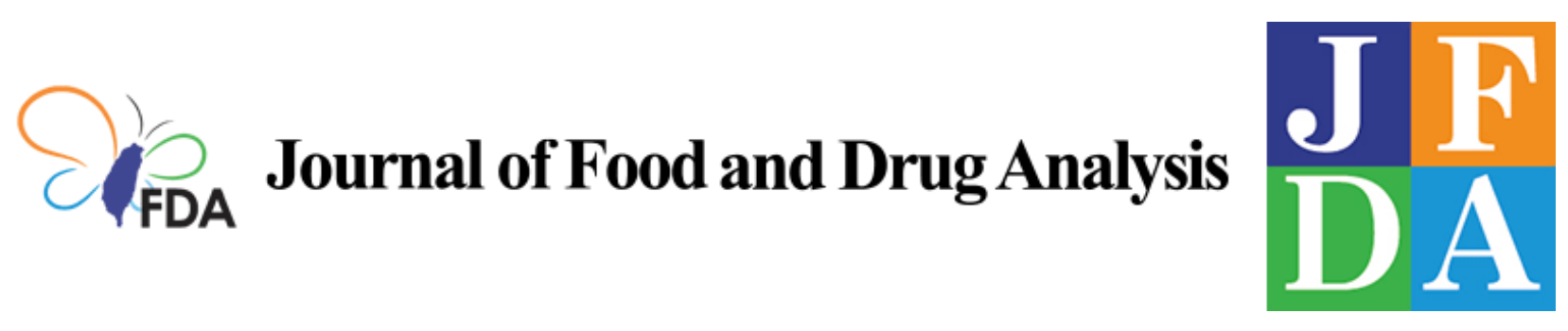

Volume 29 | Issue 3

Article 9

2021

\title{
Lucigenin-pyrogallol chemiluminescence for the multiple detection of pyrogallol, cobalt ion, and tyrosinase
}

Follow this and additional works at: https://www.jfda-online.com/journal

Part of the Food Science Commons, Medicinal Chemistry and Pharmaceutics Commons, Pharmacology Commons, and the Toxicology Commons

(c) (i) (9)

This work is licensed under a Creative Commons Attribution-Noncommercial-No Derivative Works 4.0 License.

\section{Recommended Citation}

Mostafa, Islam M.; Rehan Hasan Shah Gilani, Muhammad; Chen, Yequan; Lou, Baohua; Li, Jianping; and Xu, Guobao (2021) "Lucigenin-pyrogallol chemiluminescence for the multiple detection of pyrogallol, cobalt ion, and tyrosinase," Journal of Food and Drug Analysis: Vol. 29 : Iss. 3 , Article 9.

Available at: https://doi.org/10.38212/2224-6614.3361

This Original Article is brought to you for free and open access by Journal of Food and Drug Analysis. It has been accepted for inclusion in Journal of Food and Drug Analysis by an authorized editor of Journal of Food and Drug Analysis. 


\title{
Lucigenin-pyrogallol chemiluminescence for the multiple detection of pyrogallol, cobalt ion, and tyrosinase
}

\author{
Islam M. Mostafa ${ }^{a, b, c}$, Muhammad Rehan Hasan Shah Gilani ${ }^{a, d}$, Yequan Chen ${ }^{\text {, }}$ \\ Baohua Lou ${ }^{\mathrm{a}, \mathrm{b}, *}$, Jianping $\mathrm{Li}^{\mathrm{e}, *}$, Guobao $\mathrm{Xu}{ }^{\mathrm{a}, \mathrm{b}, *}$ \\ a State Key Laboratory of Electroanalytical Chemistry, Changchun Institute of Applied Chemistry, Chinese Academy of Sciences, \\ Changchun, Jilin 130022, PR China \\ ${ }^{\mathrm{b}}$ University of Science and Technology of China, Hefei, 230000, PR China \\ ${ }^{\mathrm{c}}$ Department of Analytical Chemistry, Faculty of Pharmacy, Minia University, 61519, Minia, Egypt \\ ${ }^{\mathrm{d}}$ Institute of Chemical Sciences, Bahauddin Zakariya University, Multan 60800, Pakistan \\ ${ }^{\mathrm{e}}$ College of Chemistry and Bioengineering, Guilin University of Technology, Guilin, 541004, China
}

\begin{abstract}
Developing new, cheap, sensitive and selective chemiluminescence (CL) systems with multiple detection properties is still a big challenge for biological and environmental applications. Here, we report a new CL system having multiple detection applications (environmental and biological). The developed lucigenin-pyrogallol system gave an enhancement (190 times) over the conventional lucigenin- $\mathrm{H}_{2} \mathrm{O}_{2} \mathrm{CL}$ system. Cobalt ion and tyrosinase can inhibit lucigenin-PG CL intensity. Based on these phenomena, we have developed new CL methods for the detection of pyrogallol $(\mathrm{LOD}=0.94 \mu \mathrm{M})$, lucigenin $(\mathrm{LOD}=0.42 \mu \mathrm{M})$, cobalt $(\mathrm{LOD}=68 \mathrm{nM})$, and tyrosinase $(\mathrm{LOD}=1.8 \mu \mathrm{g} / \mathrm{mL})$. Furthermore, the developed system gave excellent recoveries in real samples within the range of $93.59-103.12 \%$ for the assay of pyrogallol, $\mathrm{Co}^{2+}$ and tyrosinase in coffee, lake water, and human plasma, respectively.
\end{abstract}

Keywords: Chemiluminescence, Cobalt, Lucigenin, Pyrogallol, Tyrosinase

\section{Introduction}

C hallenges in the development of rapid, sensitive and selective chemiluminescence (CL) systems for numerous detecting applications have attracted tremendous research awareness for many years. Inspired by CL inherent features which include short analysis time, low background noise, wide linear dynamic range, lower detection limit, and easy availability of the instrumentation [1,2], many researchers have been studying CL. Recently, most of the researchers are looking for novel and stable coreactants for different types of luminophores like luminol and lucigenin to develops selective CL systems with multiple detections ability.

Following the discovery of luminol in 1920, another luminophore called lucigenin was discovered in 1935 and it is considered one of the most effective luminophores with extensive scope of scientific applications. Lucigenin have been paired with $\mathrm{H}_{2} \mathrm{O}_{2}$ for the first attempt in 1935 as a novel CL system [3]; however, this CL system suffered from several serious disadvantages including weak stability and poor selectivity for its real applications and implementation especially in a matrix containing metal ions as example plasma and urine [4]. Recently, researchers incorporated different synthesized nanomaterial such as quantum dots and

* Corresponding author: State Key Laboratory of Electroanalytical Chemistry, Changchun Institute of Applied Chemistry, Chinese Academy of Sciences. 5625 Renmin Street, Changchun, Jilin 130022, China. Tel/fax: +8643185262747.

E-mail addresses: loubh@ciac.ac.cn (B. Lou), likianping@263.net (J. Li), guobaoxu@ciac.ac.cn (G. Xu). 
nanoclusters into CL platforms to develop and extend the CL applications [5-7]. Despite that the numerous efforts have been made, the search for a practical and broadly useful CL system with multiple detection applications has remained very challenging.

Meanwhile the quality of food, beverages, and juices are very important issue in our life because it mainly affects our health. Phenolic compounds are commonly found in food, beverages, coffee, oils and juices. The quantification of polyphenols is important owing to their antioxidant health benefits. Also, phenolic compounds are responsible for the selfoxidation stability and organoleptic properties of foods [8-10]. What's more, in the course of recent decades, numerous specialists have concluded that eating routine food riches in polyphenolic compounds assumes a significant therapeutic role in lessening the danger of malignant growth, cardiovascular infection, inflammation, diabetes, and other degenerative diseases [11].

Pyrogallol (PG) is a natural polyphenolic compound that extensively found in different fruits, tea, crops, coffee, and many kinds of plants. It plays an important role in their quality. It is also found in many pharmaceutical dosage forms as active pharmaceutical ingredient [12]. Moreover, it is used in photography, hair dying, dying of suturing substances, and in gas analysis for adsorption of oxygen [13]. In addition, PG structural group is found in several important natural molecules such as gallic acid (GA) and tannic acid (TA). Different analytical techniques were reported for detection of PG such as spectrophotometry [14-16], chromatographic techniques [17-20], and electrochemical methods [21-24]. However, most of these methods especially chromatographic techniques involve tedious sample preparation and complicated analytical procedures that are time-consuming and use toxic organic solvents. Additionally, a little consideration has been paid to PG as a CL reagent and only a few papers have dealt with the CL oxidation of pyrogallol with different oxidants, such as periodate and $\mathrm{H}_{2} \mathrm{O}_{2}$ $[13,25-27]$. The reason for this is that CL intensity was very weak and should be enhanced by using enhancer such as surfactant, aldehyde and acid.

Cobalt ion $\left(\mathrm{Co}^{2+}\right)$ was first discovered in 1735 by George Brandt in Stockholm Sweden. It is used in many places today, such as glasses, paint pigments, magnets materials and even cancer therapy. It is one of the most important metal ions that present in our body fluid and in the surrounding environment. It is plays a significant role in different biological processes and also act as a nutrient for the human body. It is the main constituent of vitamin B12 as well as certain other metalloproteins [28]. Pernicious anemia is an example of dangerous disease related to $\mathrm{Co}^{2+}$ deficiency [29]. Other different dangerous diseases may affect human as rhinitis, lung cancer, asthma, allergic dermatitis, and pathogenic infections by the high exposure to $\mathrm{Co}^{2+}$ ions polluted environment.

Tyrosinase is a typical phenol oxidase that oxidize monophenols to o-diphenols and also oxidize odiphenols to corresponding o-quinones in the existence of molecular oxygen $[30,31]$. Its high expressing level in melanoma cancer cells makes tyrosinase a valuable biomarker for the diagnosis of melanoma cancer [32,33]. Additionally, tyrosinase possesses more functions than phenol oxidases such as catalase, peroxygenase, and catecholase [34-36]. It has broad substrate specificity toward many kinds of catechols, phenols, and quinones [37-39]. Also, PG is acting as tyrosinase substrate $[37,38,40]$.

As mentioned before, PG was used as a CL luminophore to generate a very weak CL intensity [25-27]. Also PG was detected by its enhancing effect on weak and slow lucigenin-hydroxylamine CL system in a very high concentration of sodium hydroxide $(5 \mathrm{M})$ which caused corrosion of the $\mathrm{CL}$ sample cell tube [41]. However, hydroxylamine is toxic.

In this work, we exploited for the first time the utility of PG as a new promising CL coreactant for lucigenin $C L$ without using hydroxylamine. The developed lucigenin-PG system displayed a strong CL emission in carbonate buffer, and its CL signals were strongly decreased in the presence of $\mathrm{Co}^{2+}$ and tyrosinase. Thus, it allows the multiple determination of PG, lucigenin, $\mathrm{Co}^{2+}$ and tyrosinase activity with low detection limit and excellent selectivity. Finally, the real implementation of the developed CL system is checked for the assay of PG, $\mathrm{Co}^{2+}$ and tyrosinase in coffee, lake water, and plasma samples, respectively.

\section{Experimental}

\subsection{Chemicals and materials}

PG and bovine serum albumin (BSA) were acquired from Sinopharm Chemical Reagent Co. Ltd. which located in Beijing, China. Lucigenin was acquired from TCI (Shanghai, China) and $\mathrm{H}_{2} \mathrm{O}_{2}$ was bought from Beijing Chemical Reagent Company. Tyrosinase, glucose oxidase (GOx), uric acid, dopamine, pyridoxal-5'-phosphate (PLP) and ascorbic acid were obtained from Sigma-Aldrich. Trypsin was obtained from Beijing Dingguo Changsheng Biotechnology Co., Ltd. The standard solution of lucigenin $(1.0 \mathrm{mM})$ 
was obtained by dissolving precisely $0.0510 \mathrm{~g}$ lucigenin powder in $100 \mathrm{~mL}$ of water. Various $\mathrm{pH}$ values of carbonate buffers (CB) were achieved by using sodium carbonate, bicarbonate, and small quantity of $\mathrm{NaOH}$ to control the final $\mathrm{pH}$.

Regarding the instrument used for counting the CL intensity, we have recorded the CL intensity by using a flow injection CL system (FIA-CL). FIA-CL is consisting of three compartments including; a Biophysics Chemiluminescence ultra-weak luminescence analyzer (the Institute of Biophysics, Chinese Academy of Sciences), an intelligent flow injection sampler (IFIS-C mode) (ReMax Inc., Xi'an, China), and a hand-made flow cell. In a light-tight box of the luminescent analyzer, the flow cell was placed. Injection loop with $50 \mu \mathrm{L}$ capacity for sample injection.

\subsection{Analytical procedure for PG determination}

In our experiment, we used FIA-CL system (Scheme S1) for all sample measurements. Channels $\mathrm{A}$ and $\mathrm{B}$ were loaded with water and $20 \mu \mathrm{M}$ lucigenin in $0.10 \mathrm{M} \mathrm{CB}$ solution of $\mathrm{pH}$ adjusted at 12.0, respectively. After adjusting the pump flow rate at $1.25 \mathrm{~mL} / \mathrm{min}$, two solutions (water and lucigenin) were run through the channels. Different concentrations of daily freshly prepared PG in water were injected for its determination.

\subsection{Analytical procedure for lucigenin determination}

Two channels cylinders A and B respectively were charged with $0.10 \mathrm{M} \mathrm{CB}$ solution of $\mathrm{pH} 12.0$ and $200 \mu \mathrm{M}$ PG in water. After that, two solutions were pumped with the same above mentioned flow rate. Various lucigenin solutions with various concentrations were injected for its determination.

\subsection{Analytical procedure for $\mathrm{Co}^{2+}$ determination}

Lucigenin $(20 \mu \mathrm{M})$ in $0.10 \mathrm{M}$ CB solution $(\mathrm{pH} 12.0)$ was pumped in channel $\mathrm{A}$, while double distilled water was pumped into channel $B$ at the same flow rate. Different $\mathrm{Co}^{2+}$ solutions with different concentrations were mixed well with $200 \mu \mathrm{M}$ PG in water first. After that the mixtures were injected immediately for its analysis.

\subsection{Procedure of sensing tyrosinase activity}

Double distilled water and $20 \mu \mathrm{M}$ lucigenin in $0.10 \mathrm{M} \mathrm{CB}$ solution ( $\mathrm{pH}$ 12.0) were used in our FIA cylinders $A$ and $B$, respectively. Into $10 \mathrm{~mL}$ test tubes, different concentrations of tyrosinase was mixed well with $350 \mu \mathrm{L}$ borate buffer ( $\mathrm{pH} 8.0$ ) and $200 \mu \mathrm{L}$ of PG ( $3 \mathrm{mM})$. Subsequently, the mixture was completed to $3 \mathrm{~mL}$ with distilled water and incubated at $37{ }^{\circ} \mathrm{C}$ for $2 \mathrm{~h}$. After the incubation period the mixture was injected through the loop injector for its analysis.

\subsection{Procedure of real sample preparation}

Lucigenin-PG system was further used for the assay of $\mathrm{PG}, \mathrm{Co}^{2+}$ and tyrosinase activity in coffee, lake water and human plasma samples, respectively.

For PG assay in coffee sample, coffee powder was obtained from local market and converted to fine powder with a mortar for its analysis. For $\mathrm{Co}^{2+}$ assay in lake water, water sample was obtained from the Changchun South Lake, Jilin, China. Regarding tyrosinase assay in real sample, human plasma sample was obtained from Jilin University First Hospital. The plasma sample was diluted 100 times to eliminate the interference of other components in the plasma sample. Standard addition method was applied for different real samples and the percentage recoveries were evaluated by utilizing lucigenin-PG CL system.

\section{Results and discussion}

\subsection{CL of lucigenin-PG system}

Fig. 1 represents the CL intensity of the developed lucigenin-PG system and the traditional lucigenin$\mathrm{H}_{2} \mathrm{O}_{2}$. Lucigenin-PG system shows a remarkable CL intensity ( 190 times) compared with lucigenin$\mathrm{H}_{2} \mathrm{O}_{2}$ system. It is one of the most enhanced lucigenin CL systems by comparing with other reported

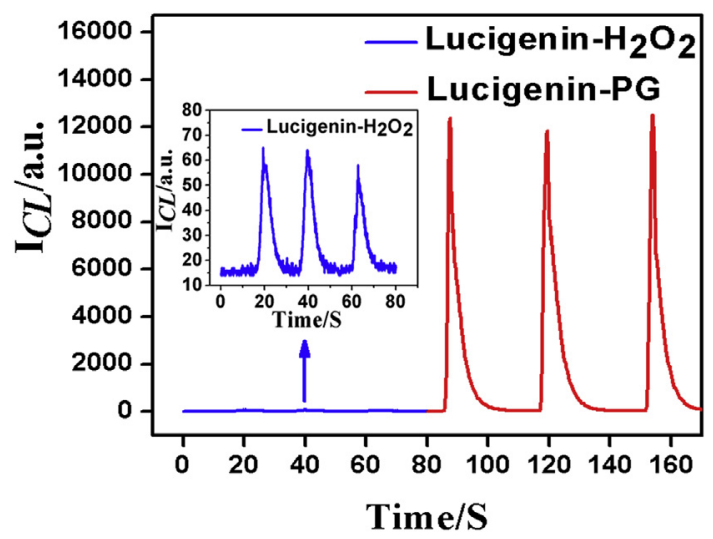

Fig. 1. The relationship between $C L$ intensities and time for the lucigenin- $\mathrm{H}_{2} \mathrm{O}_{2}$ system (blue line), and lucigenin-PG system (red line). Inset: shows the enlarged version of lucigenin- $\mathrm{H}_{2} \mathrm{O}_{2}$ curves. C(lucigenin), $20 \mu \mathrm{M}$; $\mathrm{C}(\mathrm{PG}), 1 \mathrm{mM} ; \mathrm{C}\left(\mathrm{H}_{2} \mathrm{O}_{2}\right), 1 \mathrm{mM} ; \mathrm{pH}, 12.0 ; \mathrm{PMT}, 900 \mathrm{~V}$. 
lucigenin-coreactants systems [42-46]. Besides PG, we have also investigated the effect of two other polyphenolic compounds, GA and TA. Fig. S1 shows that GA and TA gave very weak CL intensity. A comparison of the structures of PG, GA and TA indicates that $P G$ does not have carboxylic group and GA and TA have carboxylic group. The absence of electron-withdrawing carboxylic group in PG makes its autoxidation easy, resulting in intense lucigenin-PG CL. The wavelength-dependent emission spectrum was recorded by utilizing various filters ranged from 400 to $640 \mathrm{~nm}$ (Fig. S2). The highest CL intensity for the developed system was estimated at $\sim 490 \mathrm{~nm}$, which is compatible with the spectrum of lucigenin CL reported previously in the literature. It has been reported that PG autoxidized in alkaline medium to generate superoxide anion radical $\left(\mathrm{O}_{2}^{--}\right)$[13,47-49]. $\mathrm{O}_{2}^{--}$can react with lucigenin to produce an excited state of $\mathrm{N}$ - methylacridone that decays to the ground state after generating strong CL emission. Therefore the CL mechanism is proposed as seen in Scheme 1.

\subsection{Effect of dissolved oxygen on $C L$}

Lucigenin CL reaction can be initiated by superoxide anion radical $\left(\mathrm{O}_{2}^{\circ-}\right)$ which resulted from dissolved $\mathrm{O}_{2}$. So it is important to check the impact of dissolved oxygen on the developed CL system. Therefore, we have measured the CL intensity of the developed system in presence and absence of $\mathrm{O}_{2}$. Purging $\mathrm{N}_{2}$ gas into lucigenin and PG solutions for 30 min was utilized for the removal of the dissolved $\mathrm{O}_{2}$. As appeared in Fig. S3, CL intensity decreases by about $22 \%$ after the removal of $\mathrm{O}_{2}$ in the two solutions.

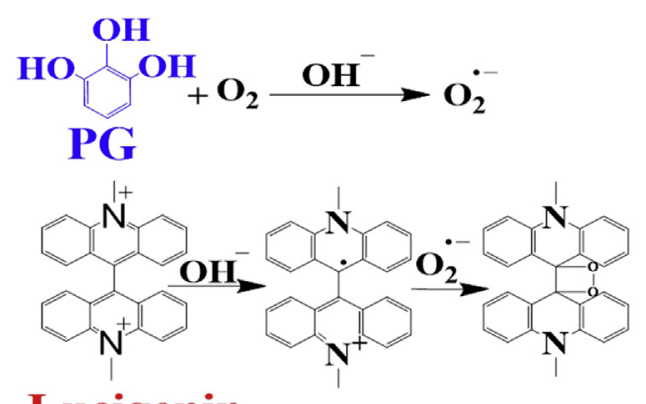

\section{Lucigenin}

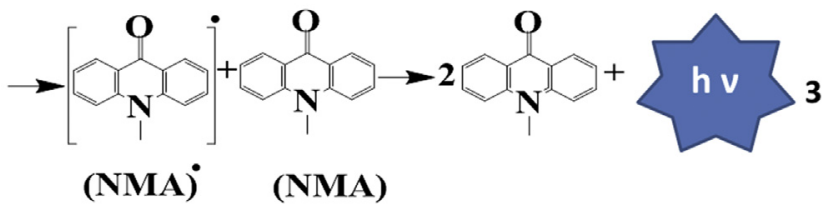

Scheme 1. Suggested reaction mechanism for lucigenin-PG CL system.

\subsection{Effect of the ionic strength and $p H$ of $C B$ solution on $C L$}

To check the effect of ionic strength of CB solution, different molar concentrations of $C B$ were used $(0.01 \mathrm{M}, 0.05 \mathrm{M}, 0.07 \mathrm{M}, 0.10 \mathrm{M}, 0.15$ and $0.20 \mathrm{M})$, while the $\mathrm{pH}$ of $\mathrm{CB}$ solution was kept constant. As shown in Fig. S4A, the highest $C L$ intensity was achieved at $0.1 \mathrm{M}$. After $0.1 \mathrm{M}$ no much increase in the CL intensity. In addition, the effect of $\mathrm{pH}$ of $0.1 \mathrm{M} \mathrm{CB}$ solution (10-12.5) was also examined to see its effect on lucigenin-PG CL system. It was clearly seen that $\mathrm{pH}$ has a great effect. CL intensity increased by increase $\mathrm{pH}$ value, as at higher $\mathrm{pH}$ values the protons of the phenolic groups were deprotonated to give phenolate anions. Phenolates anions are very rich with electron density, thus increase the autoxidation of PG and higher generation of superoxide radical that reaches its maximum at $\mathrm{pH} 11$ (Fig. S4B). After $\mathrm{pH} 11$ no much increase in the CL intensity. So, $\mathrm{pH}$ 12 of $0.1 \mathrm{M} \mathrm{CB}$ solution was selected as the optimum values for further measurements.

\subsection{Determination of lucigenin}

Using the optimized conditions, lucigenin-PG proposed system was successfully used for the determination of lucigenin. After plotting the relation between logarithm of CL intensity $(\log$ I) and concentrations of lucigenin $(\log C)$, a linear relationship was achieved from 0.5 to $120 \mu \mathrm{M}$ (Fig. 2B). The linear regression equation is $\log \mathrm{I}=2.06+0.916$ $\log C$, while correlation coefficient is $=0.9944$. The LOD was estimated to be $0.42 \mu \mathrm{M}$ for lucigenin (S/ $\mathrm{N}=3$ ). The RSD for the repeated measurements of $50 \mu \mathrm{M}$ lucigenin $(\mathrm{n}=9)$ is $3.70 \%$ (Fig. S5).

\subsection{Determination of PG}

Dependent on the high obtained CL signal intensity from the CL reaction between PG and lucigenin, the new CL system permits its detection with wide linear range in the concentration range from 1 to $100 \mu \mathrm{M}$ (Fig. 3B). The linear equation is $\log \mathrm{I}=1.36+1.23 \log C$ with a correlation coefficient of 0.9950 (where $C$ is the PG concentration in $\mu \mathrm{M})$. Applying signal-to-noise ratio of $3(\mathrm{~S} / \mathrm{N}=3)$, LOD was estimated to be $0.94 \mu \mathrm{M}$ for PG. The developed CL method shows good repeatability $(\mathrm{RSD}=2.91 \%)$ for the repeated measurements $(n=9)$ of $50 \mu$ M PG (Fig. S6).

\subsection{Interference study for PG detection}

To further assess the selectivity of proposed system for the assay of PG in coffee sample, different 

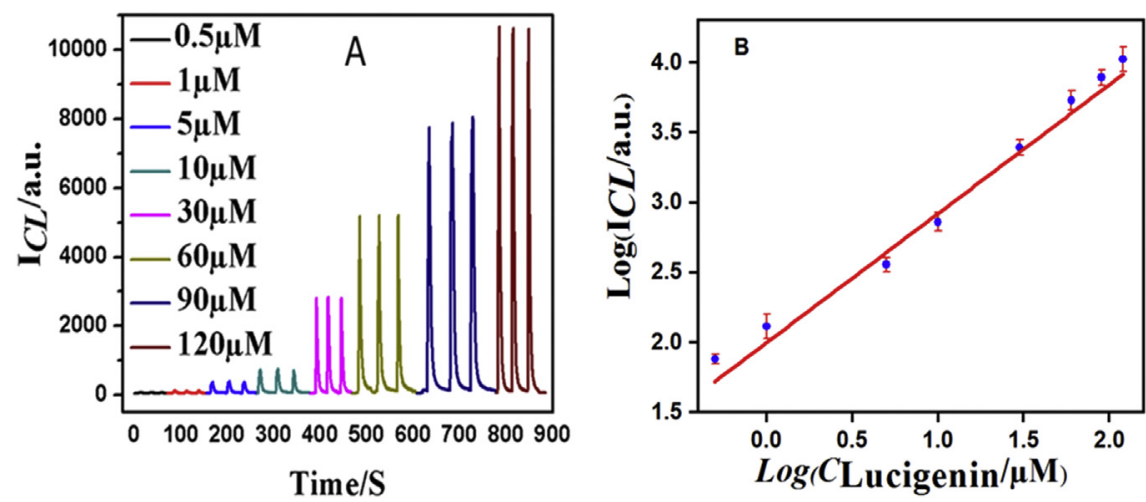

Fig. 2. (A) CL emission-time curves recorded with different concentrations of lucigenin from 0.5 to $120 \mu M$ and (B) linear relationship between $C L$ intensity and concentration of lucigenin. C(PG), $200 \mu \mathrm{M} ; \mathrm{pH}, 12.0 ; \mathrm{PMT}, 900 \mathrm{~V}$.

potential interference species in coffee were examined. To a solution containing PG, a different species were added such as TA, GA, catechin (CC), glucose (Glu), sucrose (Suc), fructose (Fru), glycine (Gly), cysteine (Cys), arginine (Arg), maleic acid (MA), citric acid (CA), $\mathrm{Ca}^{2+}, \mathrm{Cu}^{2+}$ and $\mathrm{Pb}^{2+}$. The variation of $C L$ intensity in samples corresponding to all the species is nearly negligible (Fig. 3C). This indicates that the new system has excellent selectivity toward PG assay in coffee sample.

\subsection{Determination of $\mathrm{Co}^{2+}$}

As shown in Fig. 4A, the CL intensities decreased linearly by increasing $\mathrm{Co}^{2+}$ concentrations from 0.3 to $80 \mu \mathrm{M}$. The quenching effect is due to the interaction between cobalt and PG that leads to a decrease in the autoxidation of PG to produce superoxide anion radical. Based on the quenching effect of $\mathrm{Co}^{2+}$, the proposed system was used for sensitive and selective determination of $\mathrm{Co}^{2+}$. The decrease in CL intensity vs. $\mathrm{Co}^{2+}$ concentration follows Stern-Volmer equation:

$\mathrm{I}_{0} / \mathrm{I}=1+\mathrm{K}_{\mathrm{SV}} \mathrm{C}_{\mathrm{Co}}^{2+}$

where $I_{0}$ and $I$ refer to the CL intensities of the control sample and after the addition of $\mathrm{Co}^{2+}$, respectively, $\mathrm{K}_{\mathrm{SV}}$ is the Stern-Volmer quenching constant, and $C_{\mathrm{Co}}^{2+}$ is the concentration of cobalt ion in $\mu \mathrm{M}$. The linear equation is $\mathrm{I}_{0} / \mathrm{I}=0.9886+0.307 \mathrm{C}$ $(\mathrm{r}=0.9951)$. LOD was estimated to be $68 \mathrm{nM}$ (S/ $\mathrm{N}=3$ ) that is lower than the guideline reported by Department of Environmental Protection for drinking water $(1.7 \mu \mathrm{M})$ [50]. The RSD for the repeated measurements of $5 \mu \mathrm{M} \mathrm{Co}{ }^{2+}(\mathrm{n}=9)$ is $3.40 \%$ (Fig. S7). By comparison the present work with some different reported analytical methods for assay of $\mathrm{Co}^{2+}$, the developed method is cost-effective and simple (Table S1).
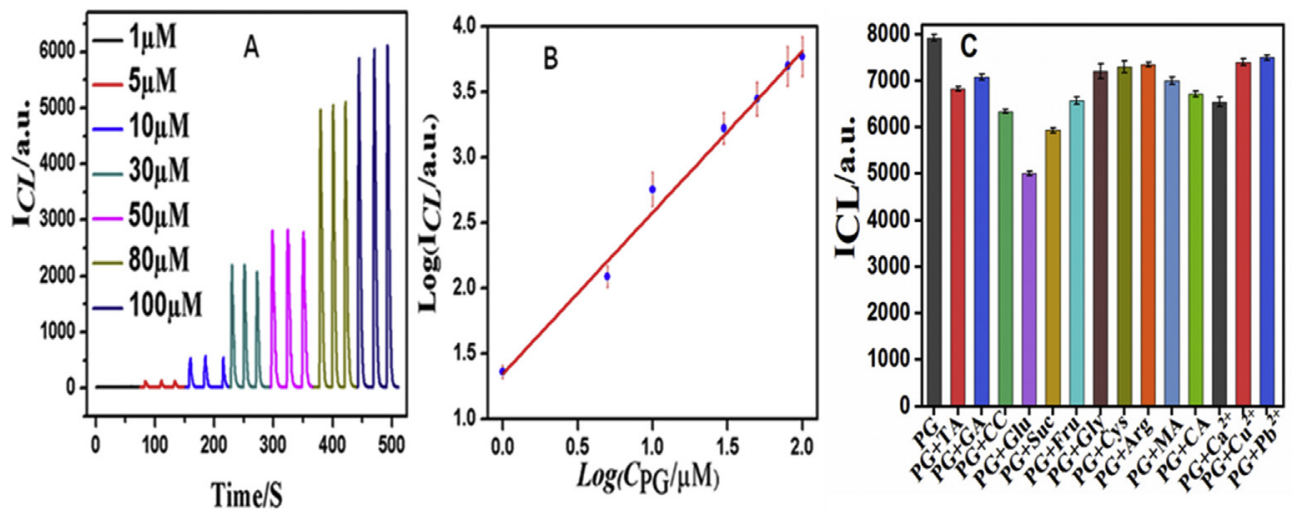

Fig. 3. (A) Repeated CL emission-time curves recorded with different concentration of PG from 1.0 to $100 \mu M$, (B) linear relationship of CL enhancement versus concentration of PG from 1.0 to $100 \mu M$ and (C) selectivity for the detection of PG. The concentration of PG is $200 \mu M$ and the interfering species (tannic acid, gallic acid, catechin (CC), glucose, sucrose, fructose, glycine, cysteine, arginine, maleic acid, citric acid, $\mathrm{Ca}^{2+}, \mathrm{Cu}^{2+}$ and $\mathrm{Pb}^{2+}$ and were $100 \mu \mathrm{M}$ for the selectivity study. C(lucigenin), $20 \mu \mathrm{M} ; \mathrm{pH}, 12.0$; and PMT, $900 \mathrm{~V}$. 

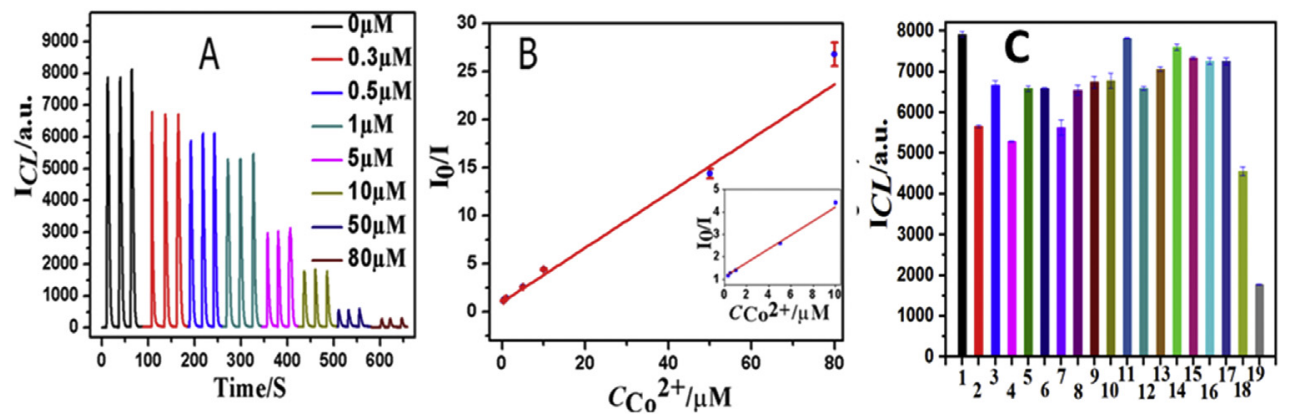

Fig. 4. (A) Repeated CL emission-time curves recorded in different concentrations of $\mathrm{Co}^{2+}$, (B) linear relationship of CL quenching versus concentration of $\mathrm{Co}^{2+}$ from 0.3 to $80 \mu \mathrm{M}$, and (C) selectivity for the detection of $\mathrm{Co}^{2+}$. The concentration of $\mathrm{Co}^{2+}$ and all the interfering metal ions were $10 \mu \mathrm{M}$ for the selectivity test. Numbers 1-19 refer to control, $\mathrm{Hg}^{2+}, \mathrm{Cu}^{2+}, \mathrm{Cd}^{2+}, \mathrm{Zn}^{2+}, \mathrm{K}^{+}, \mathrm{Mg}^{2+}, \mathrm{Ca}^{2+}, \mathrm{Fe}^{2+}, \mathrm{Sn}^{2+}, \mathrm{Li}^{+}, \mathrm{Na}^{+}, \mathrm{Mn}^{2+}, \mathrm{Pb}^{2+}, \mathrm{Cr}^{3+}$, $\mathrm{Ag}^{+}, \mathrm{Al}^{3+}, \mathrm{Ni}^{2+}$ and $\mathrm{Co}^{2+}$. C(lucigenin), $20 \mu \mathrm{M} ; \mathrm{C}(\mathrm{PG}), 200 \mu \mathrm{M}$; and pH,12.0; PMT, $900 \mathrm{~V}$.

\subsection{Selectivity study for $\mathrm{Co}^{2+}$ detection}

Selectivity study of the new system was checked by studying the potential interfering of 17 typical metal ions including $\mathrm{Hg}^{2+}, \mathrm{Cu}^{2+}, \mathrm{Cd}^{2+}, \mathrm{Zn}^{2+}, \mathrm{K}^{+}$, $\mathrm{Mg}^{2+}, \mathrm{Ca}^{2+}, \mathrm{Fe}^{2+}, \mathrm{Sn}^{2+}, \mathrm{Li}^{+}, \mathrm{Na}^{+}, \mathrm{Mn}^{2+}, \mathrm{Pb}^{2+}, \mathrm{Cr}^{3+}$, $\mathrm{Ag}^{+}, \mathrm{Al}^{3+}$ and $\mathrm{Ni}^{2+}$. Fig. $4 \mathrm{C}$ exhibits that, the $\mathrm{CL}$ intensities of lucigenin-PG system quenched significantly only by the presence of $\mathrm{Co}^{2+}$. Conversely, the controlled sample CL intensity stayed unchanged or lightly decreased by the presence of other metals. Consequently, the new system has achieved an obvious selectivity toward $\mathrm{Co}^{2+}$ determination over other metals. This remarkable selectivity is attributed to the strong and selective interaction between cobalt and PG [51,52].

\subsection{Detection of tyrosinase activity}

Tyrosinase detection involved in two steps. The first step is the catalytic oxidation of PG by tyrosinase. To measure tyrosinase activity, PG was dissolved in borate buffer ( $\mathrm{pH} 8.0)$, instead of water. The interaction of PG with borate buffer can avoid the autoxidation of PG [53,54]. Tyrosinase can catalyze the oxidation of PG in borate buffer and decrease the PG concentration. In the second step, the $\mathrm{pH}$ is increased by mixing with carbonate buffer ( $\mathrm{pH}$ 12.0) and PG autoxidation can occur at higher $\mathrm{pH}$. Since tyrosinase decreases the PG concentration, the CL intensity decreases.

Fig. 5A and B shows CL intensities and standard calibration plot for tyrosinase detection, respectively. It was observed that upon increasing tyrosinase concentrations, the CL intensity decreased and the linear range was $2-50 \mu \mathrm{g} / \mathrm{mL}$ with a limit of detection $1.8 \mu \mathrm{g} / \mathrm{mL}$. The linear equation is $\mathrm{I}_{0} /$
$\mathrm{I}=0.0529+0.9044 C$ and $\mathrm{r}^{2}$ is 0.9889 . The developed CL method shows good repeatability $(\mathrm{RSD}=2.88 \%)$ for the repeated measurements $(\mathrm{n}=9)$ of $25 \mu \mathrm{g} / \mathrm{mL}$ tyrosinase (Fig. S8).

\subsection{Selectivity study for detection of tyrosinase activity}

To further examine the selectivity of the proposed CL platform, some common interfering species, such as Glu, lactose (Lac), sucrose (Suc), Gly, glutathione (GSH), cysteine (Cys), histadine (Hist), ascorbic acid (AA), uric acid (UA), pyridoxal-5'phosphate (PLP), dopamine, BSA, trypsin, glucose oxidase (GOx), $\mathrm{Cu}^{2+}, \mathrm{Zn}^{2+}, \mathrm{Ca}^{2+}$ and $\mathrm{Mg}^{2+}$ were tested. Fig. $5 \mathrm{C}$ confirms that all the mentioned interfering species and metal ions have no significant interference on tyrosinase detection. The obtained data reveals the appropriate selectivity for the sensing of tyrosinase in biological fluid.

\subsection{Determination of $P G, \mathrm{Co}^{2+}$ and tyrosinase in real samples}

The proposed system was also used for assay of $\mathrm{PG}, \mathrm{Co}^{2+}$ and tyrosinase in coffee, lake water and in human plasma samples, respectively.

For assay of PG in coffee; coffee sample was obtained from local market and converted to powder. $0.1 \mathrm{~g}$ was accurately weighed and boiled in $50 \mathrm{~mL}$ of double distilled water for $10 \mathrm{~min}$. Then the boiled solution was cooled, filtered, diluted to $100 \mathrm{~mL}$ with water and then injected in the injection loop to evaluate the percentage recovery of the real presence of PG in coffee sample. After that, different concentrations of PG $(2,5,10 \mu \mathrm{M})$ were spiked in the coffee sample using standard addition technique. 

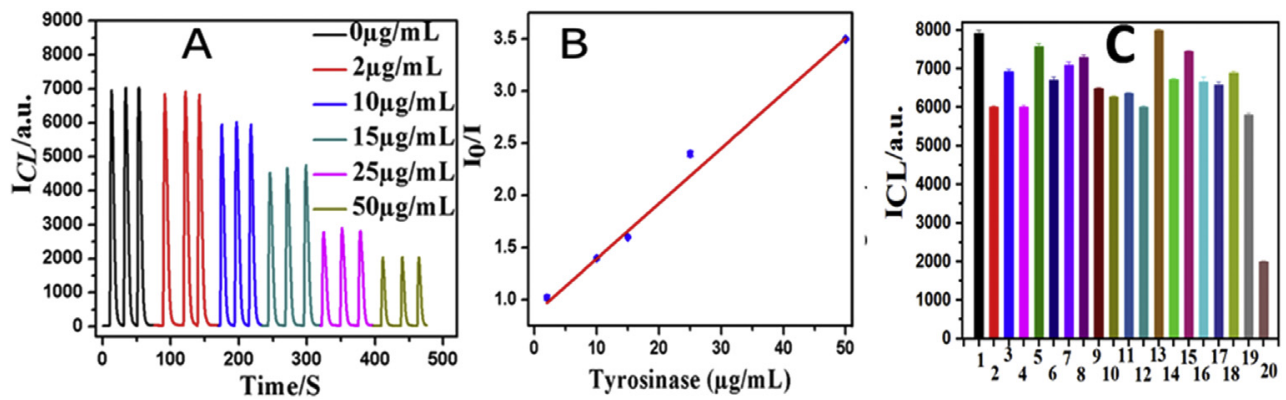

Fig. 5. (A) Repeated CL emission-time curves recorded in different concentrations of tyrosinase, (B) linear relationship of CL quenching versus concentration of tyrosinase from 2 to $50 \mu \mathrm{g} / \mathrm{mL}$, and (C) selectivity for the detection of tyrosinase. The concentration of tyrosinase is $50 \mu \mathrm{g} / \mathrm{mL}$ and the interfering species (glucose, lactose, sucrose, glycine, histadine, glutathione, cysteine, ascorbic acid, uric acid, PLP, dopamine, BSA, Cu ${ }^{2+}, \mathrm{Zn}^{2+}, \mathrm{Ca}{ }^{2+}$ and $\mathrm{Mg}^{2+}$ were $100 \mu \mathrm{M}$ and $10 \mu \mathrm{g} / \mathrm{mL}$ for GOx and trypsin for the selectivity test. Numbers from 1 to 20 refer to control, glucose, lactose, sucrose, glycine, histadine, glutathione, cysteine, ascorbic acid, uric acid, PLP, dopamine, BSA, trypsin, glucose oxidase, $\mathrm{Cu}^{2+}, \mathrm{Zn}^{2+}, \mathrm{Ca}^{2+}$ and $\mathrm{Mg}^{2+}$ and tyrosinase. C(lucigenin), $20 \mu \mathrm{M} ; \mathrm{C}(\mathrm{PG}), 200 \mu \mathrm{M}$; and $p H, 12.0 ; \mathrm{PMT}, 900 \mathrm{~V}$.

Table S2 shows the obtained percentage recoveries for the estimated samples $(97.0-103.1 \%)$.

For assay of $\mathrm{Co}^{2+}$ in lake water sample; lake water sample was obtained from the Changchun, Jilin, China. Three different concentration of standard $\mathrm{Co}^{2+}$ solutions $(7,10,50 \mu \mathrm{M})$ were spiked into water samples. Table S3 represents that, the calculated recoveries of the sample were estimated to be in the range of $94.8-100.2 \%$. The achieved results show that lucigenin-PG CL system is convenient for real lake water application.

For assay of tyrosinase in real human plasma; fresh human plasma was used for the real assay of tyrosinase activity. Three different concentrations in the calibration linear range of tyrosinase $(10,25$, $50 \mu \mathrm{g} / \mathrm{mL}$ ) were added to the plasma. After that, the percentage recoveries were calculated and listed in Table S4. The results reflect that lucigenin-PG developed system is suitable and promising for the detection of tyrosinase activity in biological samples.

\section{Conclusions}

In conclusion, lucigenin-PG CL has been found for the first time and was successfully developed for the multiple detections of lucigenin, $\mathrm{PG}, \mathrm{Co}^{2+}$ and tyrosinase. Furthermore, the proposed CL system was also used for the assay of $\mathrm{PG}, \mathrm{Co}^{2+}$ and tyrosinase in real samples with high obtained recoveries. Notably, this system achieves excellent selectivity for $\mathrm{PG}, \mathrm{Co}^{2+}$ and tyrosinase detections in real samples without interference from the presence of several species in different matrixes.

\section{Declaration of competing interest}

The authors declare no conflicts of interest.

\section{Acknowledgments}

This project was kindly supported by the National Natural Science Foundation of China [No. 21804127, and 21874126], Department of Science and Technology of Jilin Province (No. 20200703024ZP), the National Key Research and Development Program of China [No. 2016YFA0201300], and the Chinese Academy of Sciences (CAS)-the Academy of Sciences for the Developing World (TWAS) President's Fellowship Programme.

\section{Supplementary Material.}

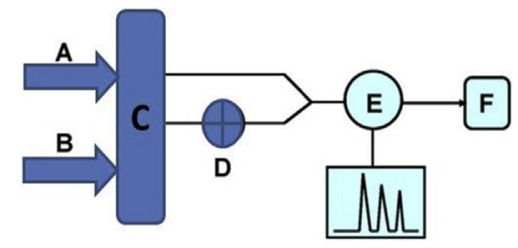

Scheme S1. Diagram of the flow injection lucigenin-PG CL system. A and B: flow channels; C: IFIS-C mode intelligent flow injection sampler; D: loop injector; E: CL detector; F: waste cup.

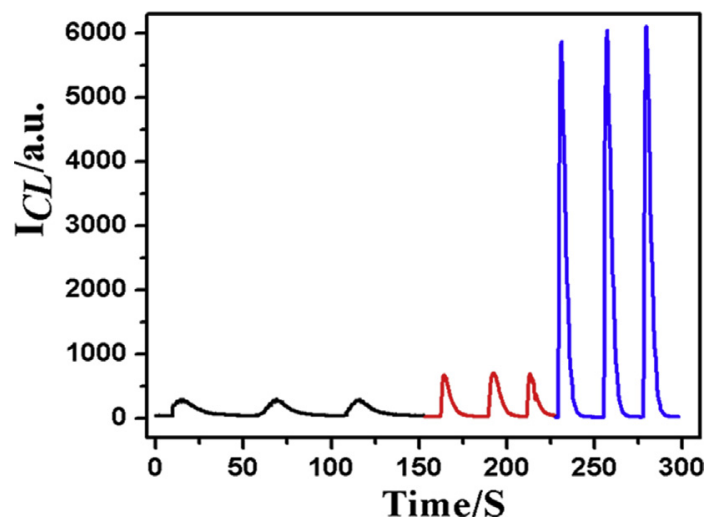

Fig. S1. CL emission-time curves recorded in the presence of $1.0 \mathrm{mM}$ TA (black color), $1 \mathrm{mM} \mathrm{GA}$ (red color), and $100 \mu \mathrm{M}$ PG (blue color). C(lucigenin), $20 \mu \mathrm{M} ; \mathrm{pH}, 12 ; \mathrm{PMT}, 900 \mathrm{~V}$. 


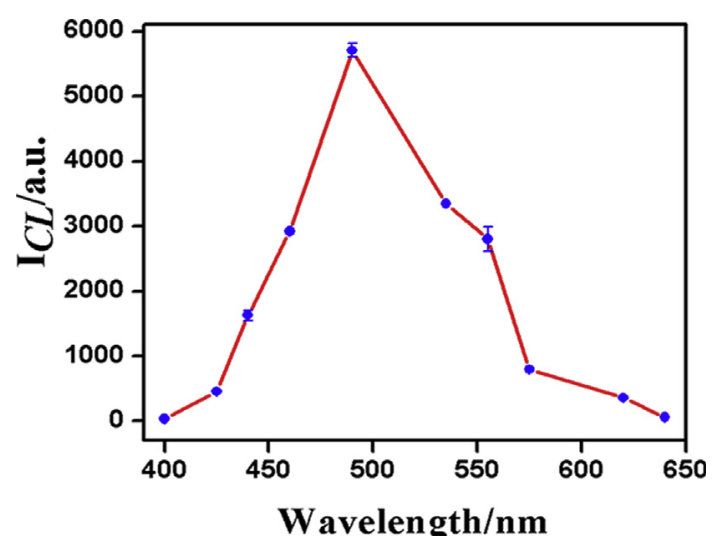

Fig. S2. CL intensity versus wavelength spectrum plotted from 400 to $640 \mathrm{~nm}$. C(lucigenin), $50 \mu \mathrm{M} ; \mathrm{C}(\mathrm{PG}), 2 \mathrm{mM} ; \mathrm{pH}, 12.0$; and PMT, $900 \mathrm{~V}$.

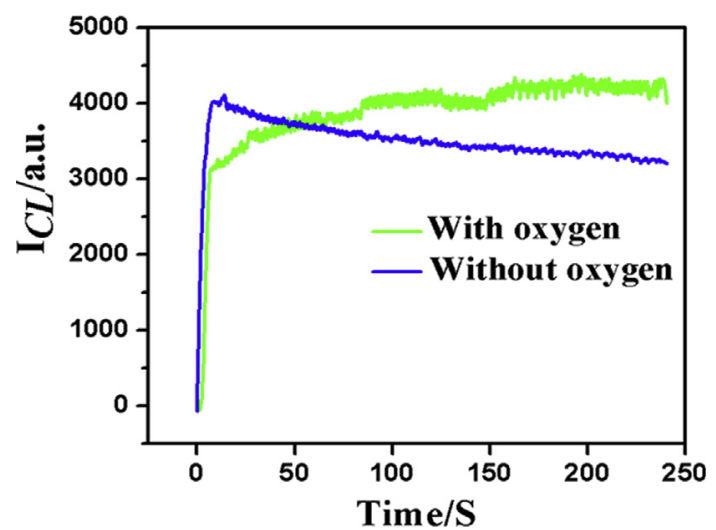

Fig. S3. CL emission-time curves recorded in the presence (green) and absence of oxygen (blue). C(lucigenin), $50 \mu \mathrm{M}$; $\mathrm{C}(\mathrm{PG}), 3 \mathrm{mM}$; $\mathrm{pH}$, 12.0; PMT, $900 \mathrm{~V}$.

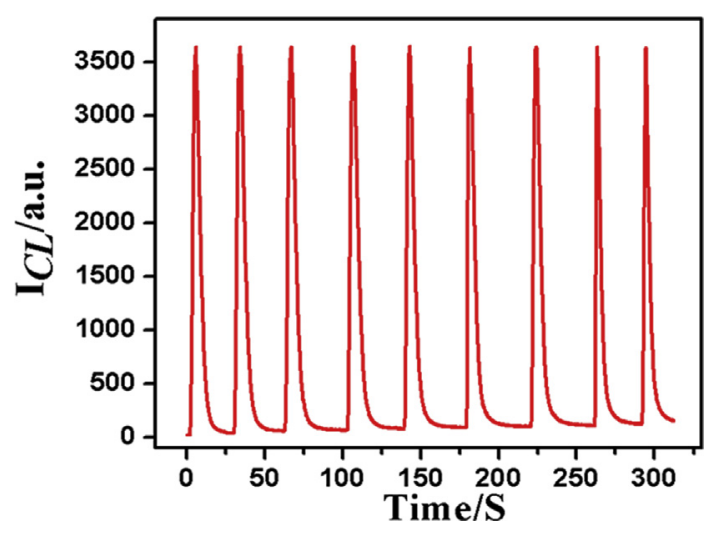

Fig. S5. CL emission-time curves at the lucigenin concentration of $50 \mu M$. C(PG), $200 \mu M ; p H, 12.0 ; P M T, 900 \mathrm{~V}$.

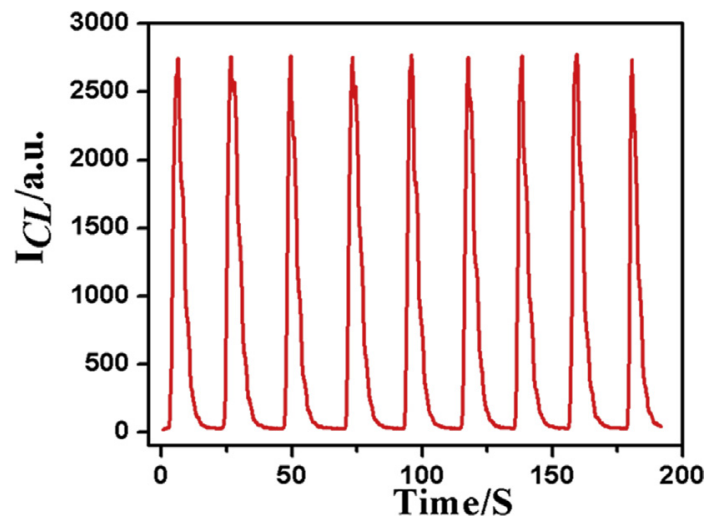

Fig. S6. CL emission-time curves at PG concentration of $50 \mu \mathrm{M}$. C(lucigenin), $20 \mu \mathrm{M} ;$ pH,12.0; PMT, $900 \mathrm{~V}$.
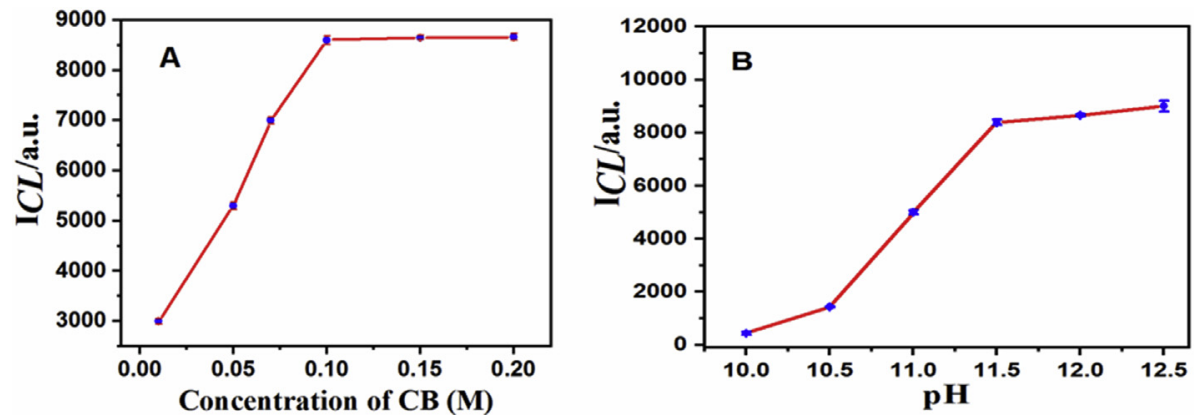

Fig. S4. CL intensity plotted as a function of (A) the ionic strength and (B) $p H$ of CB solution. C(lucigenin), $20 \mu M ; C(P G), 200 \mu M ; P M T, 900 V$. 


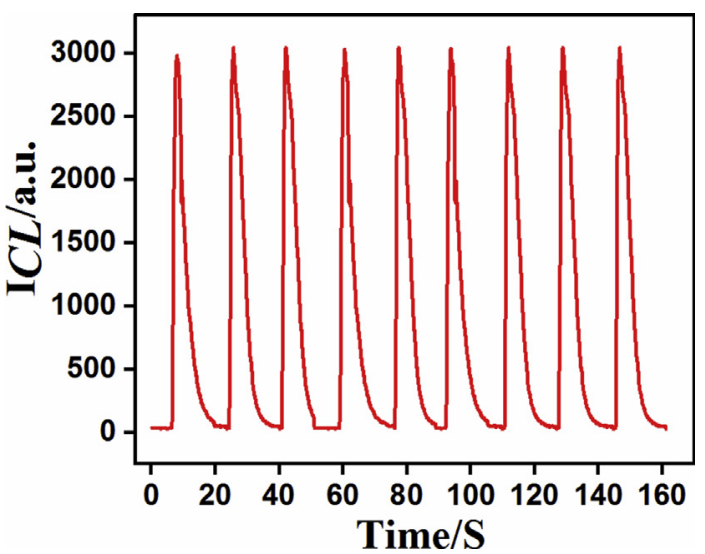

Fig. S7. CL emission-time curves for $\mathrm{Co}^{2+}(5 \mu \mathrm{M})$. C(lucigenin), $20 \mu \mathrm{M} ; \mathrm{pH}, 12.0 ;$ PMT, $900 \mathrm{~V}$.

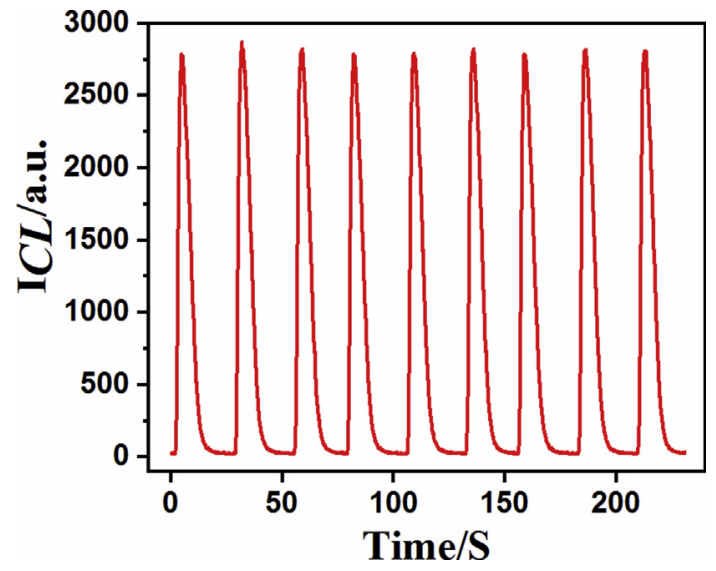

Fig. S8. CL emission-time curves for tyrosinase $(25 \mu \mathrm{g} / \mathrm{mL})$. C(lucigenin), $20 \mu \mathrm{M} ; \mathrm{pH}, 12.0$; PMT, $900 \mathrm{~V}$.

Table S1. Comparison of different methods for the detection of $\mathrm{Co}^{2+}$

\begin{tabular}{lll}
\hline Analytical Method & LOD & Ref. \\
\hline Silicon nanoparticles/Fluorescence & $0.14 \mu \mathrm{M}$ & {$[55]$} \\
N-CDs/Fluorescence & $0.68 \mu \mathrm{M}$ & {$[56]$} \\
Ag NCs/Luminescence & $100 \mathrm{nM}$ & {$[57]$} \\
Peptide modified Au NPs/Absorbance & $2000 \mathrm{nM}$ & {$[58]$} \\
Carboxyl-functionalized CdS QDs/ & $390 \mathrm{nM}$ & {$[59]$} \\
$\quad$ Absorbance & $0.3 \mu \mathrm{M}$ & {$[60]$} \\
Photoelectrochemical Detection & $0.97 \mu \mathrm{M}$ & {$[61]$} \\
Fluorescence detection & $12.4 \mu \mathrm{M}$ & {$[62]$} \\
Colorimetric detection & $0.26 \mu \mathrm{M}$ & {$[63]$} \\
Fluorescence detection & $3.25 \mu \mathrm{M}$ & {$[64]$} \\
NBS-reduced carbon QDs/ & & \\
$\quad$ Chemiluminescence & $1.25 \mu \mathrm{M}$ & {$[65]$} \\
Nitrogen and sulfur co-doped graphene & & \\
$\quad$ quantum dots/Fluorescence & $0.88 \mu \mathrm{M}$ & [66] \\
Colorimetric detection & $68 \mathrm{nM}$ & Present \\
Lucigenin-PG with FIA system/ & & work \\
$\quad$ Chemiluminescence & & \\
\hline
\end{tabular}

Table S2. Analytical results for the detection of PG in coffee.

\begin{tabular}{cllll}
\hline Sample & \multicolumn{2}{l}{ Concentrations of analyte } & Recovery & RSD $(\mathrm{n}=3)$ \\
\cline { 2 - 3 } & Amount added $^{\mathrm{a}}$ Amount found $^{\mathrm{b}}$ & & \\
\hline Coffee & $0.0 \mu \mathrm{M}$ & $4.60 \mu \mathrm{M}$ & - & $3.6 \%$ \\
& $2.0 \mu \mathrm{M}$ & $6.57 \mu \mathrm{M}$ & $99.5 \%$ & $2.5 \%$ \\
$5.0 \mu \mathrm{M}$ & $9.90 \mu \mathrm{M}$ & $103.1 \%$ & $3.0 \%$ \\
$10.0 \mu \mathrm{M}$ & $14.16 \mu \mathrm{M}$ & $97.0 \%$ & $4.9 \%$ \\
\hline
\end{tabular}

$\overline{\mathrm{a}, \mathrm{b}}$ average of three determinations.

Table S3. Analytical results for the detection of $\mathrm{Co}^{2+}$ in lake water.

\begin{tabular}{lllllll}
\hline Sample & \multicolumn{3}{l}{ Concentrations of analyte } & Recovery & $\begin{array}{l}\text { RSD } \\
(\mathrm{n}=3)\end{array}$ \\
\cline { 2 - 4 } & $\begin{array}{l}\text { Amount } \\
\text { detected }\end{array}$ & $\begin{array}{l}\text { Amount } \\
\text { added }\end{array}$ & $\begin{array}{l}\text { Amount } \\
\text { found }^{\mathrm{a}}\end{array}$ & & \\
\hline Lake water & N.D & $7.0 \mu \mathrm{M}$ & $6.63 \mu \mathrm{M}$ & $94.8 \%$ & $2.4 \%$ \\
& & $10.0 \mu \mathrm{M}$ & $9.95 \mu \mathrm{M}$ & $99.5 \%$ & $3.9 \%$ \\
& & $50.0 \mu \mathrm{M}$ & $50.11 \mu \mathrm{M}$ & $100.2 \%$ & $2.9 \%$ \\
\hline
\end{tabular}

N.D: Not detected.

${ }^{\text {a }}$ Average of three determinations.

Table S4. Analytical results for the detection of tyrosinase in plasma.

\begin{tabular}{llllll}
\hline Sample & \multicolumn{2}{l}{ Concentrations of analyte } & Recovery & $\begin{array}{l}\text { RSD } \\
(\mathrm{n}=3)\end{array}$ \\
\cline { 2 - 4 } & $\begin{array}{l}\text { Amount } \\
\text { detected }\end{array}$ & $\begin{array}{l}\text { Amount } \\
\text { added }\end{array}$ & $\begin{array}{c}\text { Amount } \\
\text { found }^{\mathrm{a}}\end{array}$ & & \\
\hline Plasma & N.D & $10 \mu \mathrm{M}$ & $9.35 \mu \mathrm{M}$ & $93.6 \%$ & $2.9 \%$ \\
& & $25 \mu \mathrm{M}$ & $24.78 \mu \mathrm{M}$ & $99.1 \%$ & $3.3 \%$ \\
& & $50 \mu \mathrm{M}$ & $49.02 \mu \mathrm{M}$ & $98.0 \%$ & $1.4 \%$ \\
\hline
\end{tabular}

N.D: Not detected.

${ }^{\text {a }}$ Average of three determinations.

\section{References}

[1] Green O, Gnaim S, Blau R, Eldar-Boock A, Satchi-Fainaro R, Shabat D. Near-infrared dioxetane luminophores with direct chemiluminescence emission mode. J Am Chem Soc 2017; 139:13243-8.

[2] Roda A, Guardigli M. Analytical chemiluminescence and bioluminescence: latest achievements and new horizons. Anal Bioanal Chem 2012;402:69-76.

[3] Gleu K, Petsch W. Die chemiluminescenz der Dimethyldiacridyliumsalze. Angew Chem 1935;48:57-9.

[4] He Y, Cui H. Synthesis of dendritic platinum nanoparticles/ lucigenin/reduced graphene oxide hybrid with chemiluminescence activity. Chem Eur J 2012;18:4823-6.

[5] Chen H, Lin L, Li H, Li J, Lin J-M. Aggregation-induced structure transition of protein-stabilized zinc/copper nanoclusters for amplified chemiluminescence. ACS Nano 2015;9: 2173-83.

[6] Wang C, Lan Y, Yuan F, Fereja TH, Lou B, Han S, et al. Chemiluminescent determination of L-cysteine with the lucigenin-carbon dot system. Microchim Acta 2020;187:50.

[7] Zhang Z-F, Cui H, Lai C-Z, Liu L-J. Gold nanoparticlecatalyzed luminol chemiluminescence and its analytical applications. Anal Chem 2005;77:3324-9.

[8] Robards K, Antolovich M. Analytical chemistry of fruit bioflavonoids A review. Analyst 1997;122:11R-34R.

[9] Bergonzi MC, Minunni M, Bilia AR. (Bio) Sensor approach in the evaluation of polyphenols in vegetal matrices. Nat Prod Commun 2008;3:2049-60. 
[10] Saura-Calixto F, Díaz-Rubio ME. Polyphenols associated with dietary fibre in wine: a wine polyphenols gap? Food Res Int 2007;40:613-9.

[11] Mariadoss AV, Vinyagam R, Rajamanickam V, Sankaran V, Venkatesan S, David E. Pharmacological aspects and potential use of phloretin: a systemic review. Mini Rev Med Chem 2019;19:1060-7.

[12] Inoue M, Suzuki R, Sakaguchi N, Li Z, Takeda T, Ogihara Y, et al. Selective induction of cell death in cancer cells by gallic acid. Biol Pharm Bull 1995;18:1526-30.

[13] Evmiridis NP, Vlessidis AG, Thanasoulias NC. Chemical analysis through CL-detection assisted by periodate oxidation. Bioinorgan Chem Appl 2007;2007. https://doi.org/ $10.1155 / 2007 / 92595$.

[14] Tomàs C, Celeste M, Cladera A, Gómez E, Estela J, Cerdà V. A new flow-injection spectrophotometric method for the determination of tannins in tea and beer using iron (III) and 1, 10-phenanthroline. Food Chem 1993;47:201-4.

[15] Moya HD, Dantoni P, Rocha FR, Coichev N. A multicommuted flow-system for spectrophotometric determination of tannin exploiting the $\mathrm{Cu}$ (I)/BCA complex formation. Microchem J 2008;88:21-5.

[16] Dmitrienko S, Medvedeva O, Ivanov A, Shpigun O, Zolotov YA. Determination of gallic acid with 4-nitrobenzenediazonium tetrafluoroborate by diffuse reflectance spectrometry on polyurethane foam. Anal Chim Acta 2002; 469:295-301.

[17] Deng Z-X, Liu L, Li W-J. A HPLC method for the determination of pyrogallol. Fine Chem Intermed 2012;42:70-2.

[18] Chunping L, Song L, Fuqiang Z, Fei R, Inspection GE-E, Bureau Q. HPLC-determination of pyrogallol by standard adding method. Modern Chem Res 2016:22.

[19] Vafaei A, Bin Mohamad J, Karimi E. HPLC profiling of phenolics and flavonoids of Adonidia merrillii fruits and their antioxidant and cytotoxic properties. Nat Prod Res 2019; 33:2531-5.

[20] Bursal E, Köksal E, Gülçin İ, Bilsel G, Gören AC. Antioxidant activity and polyphenol content of cherry stem (Cerasus avium L.) determined by LC-MS/MS. Food Res Int 2013;51: $66-74$

[21] Zhao C, Song J, Zhang J. Flow-injection biamperometry of pyrogallol compounds. Talanta 2003;59:19-26.

[22] Bao A, Xiao N, Zhu Y, Xin S, Zhang H. The electrochemical catalytic behavior of pyrogallol at an 8-hydroxyquinolinealuminum complex modified carbon paste electrode and its detection in tomato. RSC Adv 2015;5:12710-6.

[23] Araujo ASA, Caramit RP, Oliveira LCS, Ferreira VS. Electroanalytical method for determining pyrogallol in biodiesel in the presence of a surfactant. Electroanalysis 2015;27: 1152-8.

[24] Cardoso RM, Dornellas RM, Lima AP, Montes RH, Richter EM, Munoz RA. Batch-injection amperometric determination of pyrogallol in biodiesel using a multi-walled carbon nanotube modified electrode. J Braz Chem Soc 2017; 28:1650-6.

[25] Cannizzaro V, Bowie AR, Sax A, Achterberg EP, Worsfold PJ. Determination of cobalt and iron in estuarine and coastal waters using flow injection with chemiluminescence detection. Analyst 2000;125:51-7.

[26] Kearney NJ, Bridgeland ES, Jewsbury RA, Martin ND, Kelly SJ, Korn SR. Determination of pyrogallol using continuous flow with chemiluminescence detection. Anal Commun 1996;33:241-3.

[27] Nakano S, Fukuda M, Kageyama S, Itabashi H, Kawashima T. Flow injection determination of chromium (III) by pyrogallol chemiluminescence. Talanta 1993;40: $75-80$.

[28] Lindsay D, Kerr W. Cobalt close-up. Nat Chem 2011;3:494.

[29] Tvermoes BE, Finley BL, Unice KM, Otani JM, Paustenbach DJ, Galbraith DA. Cobalt whole blood concentrations in healthy adult male volunteers following twoweeks of ingesting a cobalt supplement. Food Chem Toxicol 2013;53:432-9.
[30] Halaouli SA M, Sigoillot JC, Hamdi M, Lomascolo A. Fungal tyrosinases: new prospects in molecular characteristics, bioengineering and biotechnological applications. J Appl Microbio 2006;100:219-32.

[31] Chang T-S. An updated review of tyrosinase inhibitors. Int J Mol Sci 2009;10:2440-75.

[32] Kunter U, Buer J, Probst M, Duensing S, Dallmann I, Grosse J, et al. Peripheral blood tyrosinase messenger RNA detection and survival in malignant melanoma. J Nati Cancer Inst 1996;88:590-4.

[33] Angeletti C, Khomitch V, Halaban R, Rimm DL. Novel tyramide-based tyrosinase assay for the detection of melanoma cells in cytological preparations. Diagn Cytopathol 2004;31: 33-7.

[34] Yamazaki S-I, Itoh S. Kinetic evaluation of phenolase activity of tyrosinase using simplified catalytic reaction system. J Am Chem Soc 2003;125:13034-5.

[35] Yamazaki S-I, Morioka C, Itoh S. Kinetic evaluation of catalase and peroxygenase activities of tyrosinase. Biochemist 2004:43:11546-53.

[36] Pifferi PG, Baldassari L. A spectrophotometric method for the determination of the catecholase activity of tyrosinase by Besthorn's hydrazone. Anal Biochem 1973;52:325-35.

[37] Munoz J, Garcia-Molina F, Varon R, Rodriguez-Lopez J, Garcia-Canovas F, Tudela J. Calculating molar absorptivities for quinones: application to the measurement of tyrosinase activity. Anal Biochem 2006;351:128-38.

[38] Muñoz-Muñoz JL, Garcia-Molina F, García-Ruiz PA, MolinaAlarcon M, Tudela J, Garcia-Canovas F, et al. Phenolic substrates and suicide inactivation of tyrosinase: kinetics and mechanism. Biochem J 2008;416:431-40.

[39] Munoz-Munoz J, García-Molina F, García-Ruiz P, Arribas E, Tudela J, Garcia-Canovas F, et al. Enzymatic and chemical oxidation of trihydroxylated phenols. Food Chem 2009;113: 435-44.

[40] Pavinatto FJ, Fernandes E, Alessio P, Constantino C, De Saja J, Zucolotto V, et al. Optimized architecture for Tyrosinase-containing Langmuir-Blodgett films to detect pyrogallol. J Mater Chem 2011;21:4995-5003.

[41] Li L, Lu MG. Determination of pyrogallol using a novel chemiluminescence reaction. Anal Lett 1998;31(2):343-53.

[42] Li Q, Li F, Shen W, Liu X, Cui H. Lucigenin/Co (tryptophan) 2 complex bifunctionalized graphene oxide: facile synthesis and unique chemiluminescence. J Mater Chem 2016;4: 3477-84.

[43] Alijanpour S, Akhoondi R, Chaichi M. 1-Ethyl-3-methylimidazolium ethylsulfate/copper (II) as catalyst for lucigenin chemiluminescence and its application to glucose detection. J Anal Chem 2017;72:120-7.

[44] Jia J, Zhang Y, Yin H, Wei N, Dong Y, Chu X. Black phosphorus quantum dots sensitized lucigenin chemiluminescence in mild alkaline condition and application in sensitive detection of $\mathrm{Co} 2+$. Microchem J 2020;153: 104506.

[45] Saqib M, Bashir S, Li H, Wang S, Jin Y. Lucigenin-tris (2carboxyethyl) phosphine chemiluminescence for selective and sensitive detection of TCEP, superoxide dismutase, mercury (II), and dopamine. Anal Chem 2019;91:3070-7.

[46] Lan Y, Yuan F, Fereja TH, Wang C, Lou B, Li J, et al. Chemiluminescence of lucigenin/riboflavin and its application for selective and sensitive dopamine detection. Anal Chem 2018;91:2135-9.

[47] Jian L. Increased carbon disulfide-stimulated chemiluminescence in the pyrogallol-luminol system. Luminescence 2001;16:281-3.

[48] Thanasoulias NK, Vlessidis A, Evmiridis NP. Influence of oxidant-species scavengers on the chemiluminescence (CL) emission generated during the oxidation of pyrogallol by hydrogen peroxide. Anal Chim Acta 1999;401:197-207.

[49] Marklund S, Marklund G. Involvement of the superoxide anion radical in the autoxidation of pyrogallol and a convenient assay for superoxide dismutase. Eur J Biochem 1974;47: 469-74. 
[50] Nsanzamahoro S, Cheng W, Mutuyimana FP, Li L, Wang W, Ren C, et al. Target triggered fluorescence "turn-off" of silicon nanoparticles for cobalt detection and cell imaging with high sensitivity and selectivity. Talanta 2020;210:120636.

[51] Miller RJ, Ingle Jr J. Determination of cobalt by pyrogallol chemiluminescence. Talanta 1982;29:303-11.

[52] Siegel S, Siegel B. Autoxidation of pyrogallol: general characteristics and inhibition by catalase. Nature 1958;181: 1153-4.

[53] Schmitt-Kopplin P, Hertkorn N, Garrison A, Freitag D, Kettrup A. Influence of borate buffers on the electrophoretic behavior of humic substances in capillary zone electrophoresis. Anal Chem 1998;70(18):3798-808.

[54] Morin P, Villard F, Dreux M. Borate complexation of flavonoid-O-glycosides in capillary electrophoresis: I. Separation of flavonoid-7-O-glycosides differing in their flavonoid aglycone. J Chromatogr A 1993;628(1):153-60.

[55] Nsanzamahoro S, Cheng W, Mutuyimana FP, Li L, Wang W, Ren C, et al. Target triggered fluorescence "turnoff" of silicon nanoparticles for cobalt detection and cell imaging with high sensitivity and selectivity. Talanta 2020; 210:120636.

[56] Wen X, Shi L, Wen G, Li Y, Dong C, Yang J, et al. Green and facile synthesis of nitrogen-doped carbon nanodots for multicolor cellular imaging and $\mathrm{Co} 2+$ sensing in living cells. Sensor Actuator B Chem 2016;235:179-87.

[57] Ghosh S, Anand U, Mukherjee S. Luminescent silver nanoclusters acting as a label-free photoswitch in metal ion sensing. Anal Chem 2014;86:3188-94.

[58] Zhang M, Liu YQ, Ye BC. Colorimetric assay for parallel detection of $\mathrm{Cd} 2+, \mathrm{Ni2}+$ and $\mathrm{Co} 2+$ using peptide-modified gold nanoparticles. Analyst 2012;137:601-7.
[59] Gore AH, Gunjal DB, Kokate MR, Sudarsan V, Anbhule PV, Patil SR, et al. Highly selective and sensitive recognition of cobalt(II) ions directly in aqueous solution using carboxylfunctionalized CdS quantum dots as a naked eye colorimetric probe: applications to environmental analysis. ACS Appl Mater Interfaces 2012;4:5217-26.

[60] Zheng C, Li B, Hong C, Peng A, Chen X. Chitosan as a promising hole-scavenger for photoelectrochemical monitoring of cobalt (II) ions in water. J Electroanal Chem 2019; 851:113470.

[61] Naha S, Velmathi S. "ESIPT-AIE" based sequential fluorescence 'on-off'marker for endogenous detection of hypochlorite and cobalt (II). Microchem J 2020;153:104499.

[62] Shree GJ, Murugesan S, Siva A. A highly sensitive and selective Schiff-base probe as a colorimetric sensor for $\mathrm{Co2}+$ and a fluorimetric sensor for $\mathrm{F}-$ and its utility in bio-imaging, molecular logic gate and real sample analysis. Spectrochim Acta A 2020;226:117613.

[63] Liu Y-L, Yang L, Li L, Guo Y-Q, Pang X-X, Li P, et al. A new fluorescent chemosensor for cobalt (II) ions in living cells based on 1, 8-naphthalimide. Molecules 2019;24:3093.

[64] Chen J, Yu Y, Zhang Z, Liu Z, Yan Z. NBS-rCDs(OH-) chemiluminescence analysis system for the determination of cobalt ions. Diam Relat Mater 2015;58:5-9.

[65] Boonta W, Talodthaisong C, Sattayaporn S, Chaicham C, Chaicham A, Sahasithiwat $S$, et al. The synthesis of nitrogen and sulfur co-doped graphene quantum dots for fluorescence detection of cobalt (II) ions in water. Mater Chem Front 2020;4:507-16.

[66] Rha CJ, Lee H, Kim C. Simultaneous detection of $\mathrm{Cu2}+$ and $\mathrm{Co} 2+$ by a water-soluble carboxamide-based colorimetric chemosensor. Chemistry 2020;5:1103-8. 